\section{(6) OPEN ACCESS}

\title{
Intervention to reduce heat stress and improve efficiency among sugarcane workers in El Salvador: Phase 1
}

\author{
T Bodin, ${ }^{1}$ R García-Trabanino, ${ }^{2}$ I Weiss, ${ }^{3}$ E Jarquín, ${ }_{1}^{4}$ J Glaser, ${ }^{3}$ K Jakobsson, ${ }^{5}$ \\ R A I Lucas, ${ }^{6}$ C Wesseling, ${ }^{1}$ C Hogstedt, ${ }^{1}$ D H Wegman, ${ }^{7}$ the WE Program \\ Working Group
}

${ }^{1}$ Institute of Environmental Medicine, Karolinska Institute, Stockholm, Sweden

${ }^{2}$ Association of Nephrology and Hypertension of $\mathrm{El}$ Salvador, San Salvador, El Salvador

${ }^{3}$ La Isla Foundation, Ada, Michigan, USA

${ }^{4}$ Agency for Development and Agricultural Health (AGDYSA), San Salvador, El Salvador ${ }^{5}$ Department of Public Health and Community Medicine, Gothenburg University, Gothenburg, Sweden ${ }^{6}$ School of Sport, Exercise \& Rehabilitation Sciences, University of Birmingham, Birmingham, UK DDepartment of Work Environment, University of Massachusetts Lowell, Lowell, Massachusetts, USA

\section{Correspondence to} Dr David H Wegman, Emeritus Professor University of Massachusetts Lowell, 7 Camden Place, Cambridge 02138, MA, USA: david_wegman@uml.edu

Received 7 January 2016 Revised 18 March 2016 Accepted 24 March 2016 Published Online First 12 April 2016
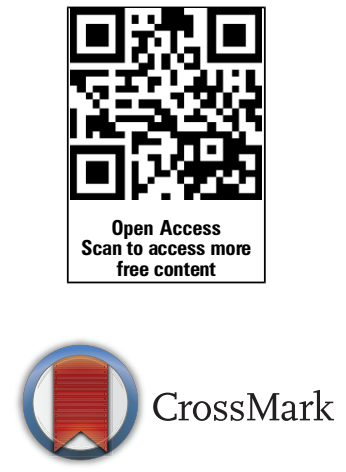

To cite: Bodin T, GarcíaTrabanino R, Weiss I, et al. Occup Environ Med 2016:73:409-416.

\section{ABSTRACT}

Background Chronic heat stress and dehydration from strenuous work in hot environments is considered an essential component of the epidemic of chronic kidney disease in Central America.

Objective (1) To assess feasibility of providing an intervention modelled on OSHA's Water.Rest.Shade programme (WRS) during sugarcane cutting and (2) to prevent heat stress and dehydration without decreasing productivity.

Methods Midway through the 6-month harvest, the intervention introduced WRS practices. A 60-person cutting group was provided water supplied in individual backpacks, mobile shaded rest areas and scheduled rest periods. Ergonomically improved machetes and efficiency strategies were also implemented. Health data (anthropometric, blood, urine, questionnaires) were collected preharvest, preintervention, mid-intervention and at the end of harvest. A subsample participated in focus group discussions. Daily wet bulb globe temperatures (WBGT) were recorded. The employer provided individual production records.

Results Over the harvest WBGT was $>26^{\circ} \mathrm{C}$ from 9:00 onwards reaching average maximum of $29.3 \pm 1.7^{\circ} \mathrm{C}$, around 13:00. Postintervention self-reported water consumption increased $25 \%$. Symptoms associated with heat stress and with dehydration decreased. Individual daily production increased from 5.1 to a high of 7.3 tons/person/day postintervention. This increase was greater than in other cutting groups at the company. Focus groups reported a positive perception of components of the WRS, and the new machete and cutting programmes.

Conclusions A WRS intervention is feasible in sugarcane fields, and appears to markedly reduce the impact of the heat stress conditions for the workforce. With proper attention to work practices, production can be maintained with less impact on worker health.

\section{BACKGROUND}

Mesoamerican nephropathy (MeN), an epidemic of chronic kidney disease (CKD) unrelated to diabetes or hypertension, is taking a huge toll on agricultural communities throughout Central America. ${ }^{1}$ El Salvador is one of the hotspots. ${ }^{2-4}$ Though much remains to be learned about $\mathrm{MeN}$, there is consensus that sugarcane workers are the most affected

\section{What this paper adds}

- There is an epidemic of chronic kidney disease of unknown cause in Central America concentrated in sugarcane workers.

- Excessive heat exposure and dehydration combined with strenuous physical labour is suggested as the central element of the epidemic.

- Appropriate access to water, rest and shade during each workday offers important relief from the high level of heat stress experienced by sugarcane cutters.

- Added rest can be provided effectively while applying ergonomic principles to maintain adequate productivity.

- Physically demanding jobs in hot climates require appropriate access to water, rest and shade, especially in the context of global climate change.

population, and that enough is known about some occupational risk factors to intervene and mitigate unnecessary death and suffering. ${ }^{5}$

Chronic heat stress and dehydration from strenuous work in hot environments is considered an essential component of the epidemic. ${ }^{1} 56$ Heat exposure during sugarcane cutting is so extreme that, during part of the workday, workers should only labour 15 min out of each hour, according to OSHA guidelines. ${ }^{7} 8$ The reality witnessed in Central America is very different.

Sugarcane cutting is work with high cardiovascular demand comparable to endurance athletes or elite soldiers during multiday operations or events, although sugarcane workers undertake such highintensity work day after day throughout the harvest season. ${ }^{9-11}$ The metabolic heat production from strenuous work in an uncompensated thermal environment determines that autonomic heat loss mechanisms (ie, sweating and skin blood flow) cannot maintain a thermal steady state. ${ }^{12}$ Daily water needs due to loss of body water during vigorous exercise in hot climate can reach up to $12 \mathrm{~L}$, and demands longer recovery periods $(\sim 24 \mathrm{~h})$ with adequate fluid and nutrient (including electrolyte) 
replacement. ${ }^{13}{ }^{14}$ Insufficient fluid recovery causes dehydration which exacerbates heat strain. ${ }^{14}$ Without appropriate responses (halting physical work, seeking shade, drinking fluids, etc), internal body temperature will rise, impairing performance (both mental and physical) and potentially leading to injury and to heat illness, heat stroke and even death. ${ }^{10}$

Recent animal studies have identified mechanistic pathways for how chronic recurrent dehydration and/or acute kidney disease may lead to CKD. ${ }^{15}{ }^{16}$ Additionally, epidemiological evidence for a causal association between $\mathrm{MeN}$ and chronic heat stress and dehydration is mounting. ${ }^{4-19}$ Hence, chronic cyclic heat stress and dehydration from strenuous work in hot environments remains a key focus of the aetiology for the epidemic.

Other still unknown factors have been suggested to play a role in the MeN epidemic, ${ }^{1} 2021$ in particular, pesticides. ${ }^{22-26}$ However, the overall evidence for pesticides is scant, ${ }^{5} 27$ just as it is for other suggested risk factors including nephrotoxic medications, alcohol, arsenic, cadmium, silica and infectious

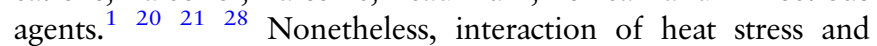
demanding work could impact uptake of toxins if exposure to these is documented. ${ }^{29}$

The Worker Health and Efficiency Program Working Group is conducting a multiphase intervention study during cane cutting in El Salvador with the primary objectives to prevent heat stress and dehydration without decreasing productivity. This intervention broadly follows OSHA's Water.Rest.Shade (WRS) programme for people working in hot temperatures. ${ }^{8}$ Efficiency improvements use expertise from the Australian sugarcane industry. A secondary objective is to determine whether this intervention will result in reduced health consequences from heat stress and dehydration, with or without evidence of preserved kidney function over the day and over the harvest.

Here we report the overall methods and lessons learned from Phase 1 of the intervention, which assessed (1) the feasibility of providing a WRS programme while improving cutting techniques and work processes, (2) evidence that the intervention reduced worker heat stress and (3) feasibility of extensive data collection for Phase 2 evaluation of the intervention in addressing the broader health issues.

\section{MATERIALS AND METHODS}

\section{Context and preintervention work conditions}

The El Salvador sugarcane industry employs approximately 11000 cane cutters during the November to April harvest period. In the remaining months of the year, the cutters work various other jobs, mostly in farming.

The present study was conducted at one of the largest sugar mills, Ingenio El Ángel (henceforth: the mill), whose operations provide work to approximately 4000 cane cutters via a variety of subcontracting arrangements. The leadership of the study mill has been in the vanguard of the issues of occupational health, child labour and workers' rights. The workers are organised in 'frentes de roza' (cutting fronts) consisting of 40-70 workers led by a 'caporal' (supervisor). The caporales report to a subcontractor, cooperative or landowner who sells the cane to the mill. Workers are paid piecework wages, based on tons ${ }^{30}$ or area cut. ${ }^{18}$ The workers live in nearby communities and are transported to sugarcane fields at dawn in the caporal's truck or bus.

Cane fields are burned the night before cutting to remove vegetation, concentrate sugar crystals in the cane, and eliminate rats, snakes and other infectious or poisonous vectors. Workers use mill-provided machetes, shirts, hats, gloves and shin guards. The cutting process begins by cutting the stalk a few centimetres above ground level by swinging a machete to shoulder level while bending at the knees and/or waist. Workers either top each stalk as it is cut, or stack them and top the cut stalks lying on the ground. After cutting enough stalks, the cane is gathered by hand, moved to a pile to be 'grabbed' by a tractor's crane attachment ${ }^{7}$ and loaded on a truck for transport to the mill. A 'checker' records each 'grab' (colloquially 'garrada', $\sim 1 \frac{1}{2}$ ton) as the basis for worker wages.

A worker's daily cutting section is generally six rows across, $25-50 \mathrm{~m}$ long. Workers bring water to the field, usually in gallon-sized plastic containers, meant to last for the full day. The container is left at the beginning of the cutting area or carried by the worker as he travels across the assigned area, variably walking back to drink from the container. All work is done under direct sunlight.

\section{Environmental measurements}

Wet bulb globe temperature (WBGT) was measured in the cane fields from 1 December 2014 until the end of the harvest. A QUESTemp 34 (3 M) recorded dry bulb, wet bulb, globe temperature and relative humidity at $15 \mathrm{~min}$ intervals. The device was placed at waist level in the open field and monitored by a trained assistant over the entire workday. The device automatically calculates and records WBGT as:

$$
\begin{aligned}
\text { WBGT }= & 0.7 \times \text { wet bulb }+0.2 \times \text { globe temperature }+0.1 \\
& \times \text { dry bulb }
\end{aligned}
$$

Two-weekly measurements by WeatherHawk 232 Direct Connect Weather Station were highly correlated, so only WBGT is reported.

\section{The intervention}

Two groups of cane cutters were invited to the study. The Inland group (the $\sim 70$ workers in one front) lived between the towns of Suchitoto and San José Guayabal in central El Salvador, at $\sim 450 \mathrm{~m}$ altitude. The Coastland group ( 660 workers from a larger front) near San Luis Talpa, a sea-level south-central region. The two groups represented two distinct environments, but otherwise similar in cane cutting.

Both groups participated in a preharvest baseline examination, and an end-of-harvest follow-up; the Inland group participated in two intermediate examinations as well. Table 1 describes participation over the harvest period. The WRS intervention ${ }^{8}$ and efficiency training were provided to the Inland group starting in January 2015, 2 months into the 5-month harvest season. The original plan was to initiate the same intervention in the Coastland group but poor participation along with security concerns led to delaying their intervention to the next harvest.

\section{Water.Rest.Shade}

A rest programme was designed with all rest occurring in the shade of a portable canopy (figure 1) that moved progressively alongside the cane cutting teams throughout each workday. Early morning is cooler, with temperature rising steeply at around 09:30. Consequently, the schedule began with a $1.5-2 \mathrm{~h}$ working interval at the start of the day followed by hour-long work periods thereafter, broken by $10-15 \mathrm{~min}$ rest breaks and a 45 min lunch break.

Each worker was supplied with a $3 \mathrm{~L}$ backpack mounted water bladder with connected flexible tube and mouthpiece (CamelBak) for continuous hydration. The model used was created for US Special Forces engaged in desert warfare. The insulated, antimicrobial bladders are designed for minimal 
Table 1 Pattern and type of data collection for two study groups

\begin{tabular}{|c|c|c|c|c|c|c|c|}
\hline & Baseline & Biweekly Nov/Dec & Preintervention & Biweekly Jan/Feb & Mid-term & Biweekly Mar/Apr & End of harvest \\
\hline Number of field visits & 1 & 2 & 1 & 2 & 1 & 3 & 1 \\
\hline \multicolumn{8}{|l|}{ Participants } \\
\hline Inland & 56 & 37 & 42 & 41 & 41 & 41 & 41 \\
\hline Coastland & 60 & 21 & 13 & & & & 41 \\
\hline Questionnaire & Yes & Yes & Yes & Yes & Yes & Yes & Yes \\
\hline Physical exam & Yes & & Yes & & Yes & & Yes \\
\hline \multicolumn{8}{|l|}{ Biomonitoring } \\
\hline Haemogram* & Yes & & Yes & & Yes & & Yes \\
\hline Serumt & Yes & & Yes & & Yes & & Yes \\
\hline Basic urine $\ddagger$ & Yes & Yes & Yes & Yes & Yes & Yes & Yes \\
\hline Extended urine§ & Yes & & Yes & & Yes & & Yes \\
\hline WBGT & \multicolumn{7}{|c|}{ Daily in both groups } \\
\hline \multicolumn{4}{|l|}{ Water refills } & \multicolumn{4}{|c|}{ Daily self-report (Inland group) } \\
\hline \multicolumn{4}{|l|}{ Difficulty of work } & \multicolumn{4}{|c|}{ Weekly assessment (Inland group) } \\
\hline
\end{tabular}

movement during activity in extreme heat and need only annual cleaning.

The CamelBaks were refilled at rest breaks with water maintained in $40 \mathrm{~L}$ coolers placed under each shade canopy. The coolers were filled daily with fresh water from a water truck brought to the field by the mill. At the end of each day individuals reported number of CamelBak refills.

\section{Efficiency training}

Two Australian cane cutting experts, one a world champion manual cane cutter, ${ }^{31}$ made the following recommendations for improved efficiency:
1. A redesigned machete for improved ergonomics. The Australian designed machete introduced was lighter with an ergonomic handle design and an angled curve in the middle of the blade. Whereas the flat end of the blade was used for cutting with the original machete, the curve in the new machete resulted in less bending.

2. A reduced number of rows cut (from six to four or five), and improved stacking method in order to reduce lateral carrying distance and workload.

The Australian experts visited the fields, demonstrated the new methods to mill engineers and workers, and trained workers on how to use the machete during a 3-week period.

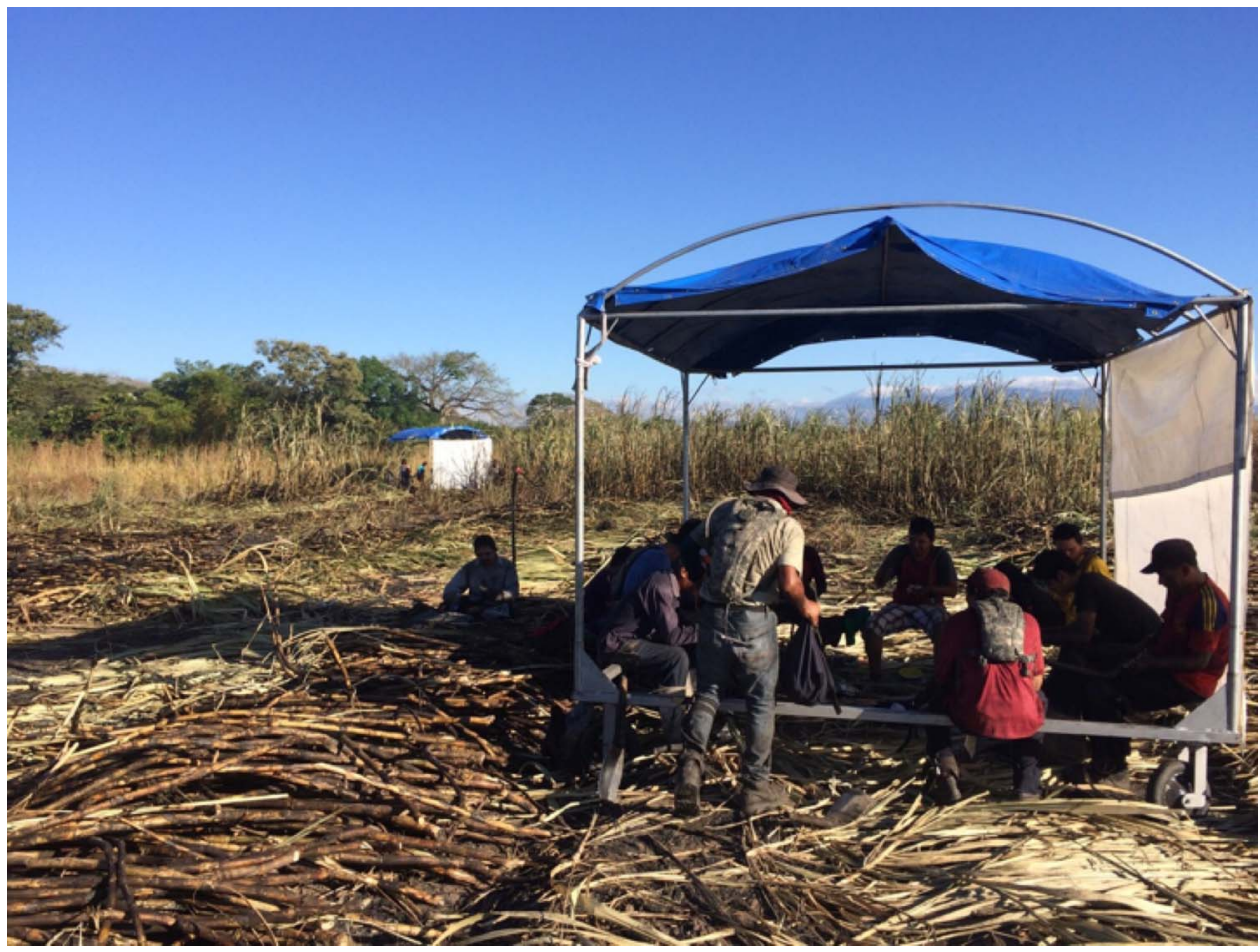

Figure 1 Workers in the cane field taking a break in the shade provided by the mobile canopies (note the wheels on the frame and the CamelBaks). 
The mill's daily records (tons/individual) were used for evaluation of productivity.

\section{Questionnaires and measures of health outcomes}

All participants had a baseline examination 1 week before the start of the harvest. The examination took place in each of the two communities where the workers lived. Workers arrived early in the morning at the same time that fieldwork usually begins.

After signing an informed consent, participants were weighed, had their height measured on a combined digital weighing scale with a mechanical height rod (SECA electronic AD 769, Seca, Birmingham, UK), and body mass index was calculated. Blood pressure and heart rate were measured once after the participant had been seated for a minimum of five minutes using a digital system (Omron HEM 7220, Omron Healthcare Inc, Bannockburn, Illinois, USA). Venous blood and urine samples were collected.

A standardised 45 min interview included questions regarding sociodemographic data; past and present work history including exposure to occupational and environmental hazards focusing on heat, cane-burning and pesticides; use of tobacco, alcohol and recreational drugs; general health including history of hypertension and diabetes; current bodily pains; medication used for reported conditions as well as use of other known nephrotoxic substances; family history of CKD; and past and present heat stress and dehydration symptoms.

During biweekly (every 2 weeks) field visits to the Inland (intervention) group (table 1), a shortened 10 min questionnaire was administered asking about the difficulty of assigned work, hydration, current occupational hazards, medication use, heat stress symptoms and bodily pain.

Additionally, research assistants used a survey form to collect information on Camelbak refills from each worker (daily), use of the new machete (weekly) and difficulty of cane being cut (weekly).

In the Inland group, the sampling consisted of preshift and postshift blood and urine samples collected at three occasions during the harvest; the second week of January (right before the intervention), in March (mid-intervention) and mid-April (final week of the harvest). Additional urine samples were collected preshift and postshift every second week throughout the harvest. In the Coastland group, only baseline and end-of-harvest samples were obtained for the majority of workers (table 1 ).

\section{Qualitative evaluation}

A qualitative evaluation of Phase 1 was conducted near the end of the harvest by researchers external to the implementation of the intervention. Five focus groups (45-60 min) were organised with 5-11 participants, two for cane cutters (younger and older, in the field), and one each for family members (in a home), company employees in charge of the intervention (in a meeting room) and research assistants (in a restaurant). An emergent design was used permitting flexibility in posing questions and obtaining complementary indepth information through individual interviews. The topics addressed were water, rest and shade, the new machete, the data collection, and the participation of the various actors in the programme.

\section{Analysis}

WBGT values were summarised as hourly averages by day and grouped into categories to determine proportion of work-time spent with respect to OSHA work-limit guidelines $\left(\geq 26,<28^{\circ}\right.$ $\mathrm{C}=25 \%$ rest; $\geq 28, \quad<30^{\circ} \mathrm{C}=50 \%$ rest; $\geq 30^{\circ} \mathrm{C}=75 \%$ rest $) .{ }^{8}$
Intervention impact was assessed comparing mean individual production (tons/person/day), water intake (L) and symptom occurrence (per cent preintervention and postintervention) in the Inland group. Mean individual production and average individual change in production for the Inland group were compared with the five most productive (of 27 total) cutting fronts of the mill. Focus groups and interview data were transcribed and organised by group type then assessed for risk and illness perceptions before and after the intervention.

\section{RESULTS}

\section{Study population}

Over the course of the harvest, approximately 70 workers in the Inland group worked at least briefly. Fifty-six appeared for baseline testing, and of these, 14 discontinued working early and did not return for subsequent testing. In the Coastland group, the caporal supervised a cutting front of 300 workers divided into five subfronts. Sixty workers from different subfronts appeared at baseline, and of these 15 never started working or discontinued work early. Out of the remaining 45 workers, all but 13 ceased participation during the harvest. This happened mainly because we dealt with the caporal only and not with the subgroup leaders, which made communication routes less effective. Owing to this markedly reduced participation, and added to the gangrelated security issues that emerged in the coastlands, we chose not to initiate the intervention in the Coastland group during Phase 1. However, an end-of-harvest examination was possible to perform in both groups (table 1). Workers received US\$8 for each of the four sampling days in which they participated.

Both groups were predominantly male, with $2 \%$ and $12 \%$ of female workers (none pregnant) in the Inland and Coastland groups, respectively. Ages ranged from 18 to 63, with only 12 out of $116>50$ years old. Women and men performed the same cane-cutting tasks. There were a few differences in occupational histories between the groups (table 2). There were no migrant workers in either study group.

\section{Heat exposure}

Early morning (06:00-07:00) WBGT measures were cooler inland than coastland $\left(17.8^{\circ} \mathrm{C} \pm 2.3^{\circ} \mathrm{C}\right.$ vs $\left.21.5^{\circ} \mathrm{C} \pm 2.0^{\circ} \mathrm{C}\right)$. For the Inland group, WBGT remained, on average, $<26^{\circ} \mathrm{C}$ until after 09:00, thereafter steadily increasing until midday. In the Coastland group, WBGT increased more rapidly, with WBGT $<26^{\circ} \mathrm{C}$ only until 08:00. Across the harvest, this pattern was replicated with the average maximum hourly WBGT inland $29.3^{\circ} \mathrm{C} \pm 1.7^{\circ} \mathrm{C}$, and coastland $31.0^{\circ} \mathrm{C} \pm 1.5^{\circ} \mathrm{C}$ typically reached 13:00-13:30 in the inland, and 11:30-12:30 at the coastland (figure 2).

The working conditions for the two groups differed with respect to length of workday and to level of heat stress exposure. The Inland group worked $8-10 \mathrm{~h}$, including a lunch break, with meals provided by the mill (starting typically at 06:00, finishing around 15:00), while the Coastland group finished their workday before lunch, usually after $4-5 \mathrm{~h}$ of work (starting similarly at 06:00, finishing around 11:15). With scheduled breaks, the Inland group rested $25 \%$ of the workday, but still worked outside OSHA-recommended work/rest periods $42 \%$ of the time. The Coastland group worked only $60 \%$ of the Inland group's total harvest hours. However, without any scheduled breaks they spent $74 \%$ of their hours outside OSHA guidelines, and half of those hours were at levels $\left(>30^{\circ} \mathrm{C}\right.$ WBGT) where OSHA recommends $75 \%$ rest. Even had the Coastland group also rested $25 \%$ of the time, it would have exceeded the recommended work limits $59 \%$ of the time. 
Table 2 Basic sociodemographic data and exam findings by study group

\begin{tabular}{|c|c|c|}
\hline & Inland & Coastland \\
\hline & $n=56$ & $\mathrm{n}=60$ \\
\hline & n (\%) & $\mathrm{n}(\%)$ \\
\hline Male & $55(98 \%)$ & $46(77 \%)$ \\
\hline Female & $1(2 \%)$ & $14(23 \%)$ \\
\hline \multicolumn{3}{|l|}{ Work history in } \\
\hline Cotton & $1(2 \%)$ & $18(30 \%)$ \\
\hline Other agriculture & $49(88 \%)$ & $42(70 \%)$ \\
\hline Construction & $23(41 \%)$ & $28(47 \%)$ \\
\hline Mining & $0(0 \%)$ & $1(2 \%)$ \\
\hline \multicolumn{3}{|l|}{ Current smokers } \\
\hline Males & $18(33 \%)$ & $11(24 \%)$ \\
\hline Females & $0(0 \%)$ & $0(0 \%)$ \\
\hline \multicolumn{3}{|l|}{ Alcohol consumption } \\
\hline Males (sometimes) & $21(38 \%)$ & $18(39 \%)$ \\
\hline Males (often/every day) & $1(2 \%)$ & $1(2 \%)$ \\
\hline Females (sometimes) & $0(0 \%)$ & $3(21 \%)$ \\
\hline Females (often/every day) & $0(0 \%)$ & $0(0 \%)$ \\
\hline Mother or father with CKD & $4(7 \%)$ & $6(10 \%)$ \\
\hline Systolic ABP >140 & $11(20 \%)$ & $8(13 \%)$ \\
\hline \multirow[t]{2}{*}{ Glucosuria } & $1(2 \%)$ & $0(0 \%)$ \\
\hline & Mean (SD) & Mean (SD) \\
\hline Age (years) & $34(12)$ & $33(11)$ \\
\hline Education (years) & $5.9(3,6)$ & $4.9(3,6)$ \\
\hline Harvests worked (number of seasons) & $7.1(7)$ & $7.6(6,7)$ \\
\hline BMI $\left(\mathrm{kg} / \mathrm{m}^{2}\right)$ & $24.1(3,9)$ & $23.8(4,5)$ \\
\hline Systolic ABP (mm Hg) & $129(12)$ & $123(14)$ \\
\hline Diastolic ABP (mm Hg) & $75(11)$ & $71(8)$ \\
\hline
\end{tabular}

\section{Intervention impact}

Water consumption

Using all available biweekly data, self-reported water consumption in the Inland group increased postintervention on average from 5.1 to $6.3 \mathrm{~L}$ daily, a difference of $1.2 \mathrm{~L}$ (95\% CI 0.8 to 1.6).

\section{Production change}

Individual daily average production in the Inland group increased over the course of the harvest improving from 5.1 tons/person/day at the intervention start to 7.3 tons/person/ day in the penultimate period. There was an expected drop in total production in almost all groups during the last weeks, when generally smaller fields are cleared.

When production in the intervention group was compared with the five most productive cutting fronts, the proportionate increase in individual average daily production, preintervention and postintervention, was significantly better for the intervention group compared with each of the other groups $(\mathrm{p}<0.05$ in all cases).

\section{Symptoms of heat stress}

Preliminary analysis of symptoms related to heat stress and dehydration before and after the intervention showed a general reduction in these symptoms (figure 3). Most symptoms of heat exhaustion decreased substantially, especially for feeling feverish, exhaustion, nausea and cramps. Some symptoms of dehydration (the occurrence of very dry mouth and very little urine) decreased substantially postintervention, but reports of dark urine and dysuria did not change. These latter findings are being further explored. Few workers reported fainting and vomiting at any time during the harvest.

Qualitative findings on impact of the intervention

Overall, the focus groups revealed a positive perception of the new machete. The workers attributed less musculoskeletal pains to the lighter tool. Workers also reported they cut more cane even with the rest periods. The lighter blade, however, wore down somewhat more rapidly.

Most workers reported they adapted well to the CamelBak, and had more access to water of higher quality (cool and clean). Workers welcomed the rest periods, which they used for refilling the CamelBaks, drinking more water, sharpening their machete, and even communicating with their families. The access to shade during the scheduled rest was especially commented upon positively.

Both groups of workers as well as family members and the health personnel assisting in the data collection perceived an
Figure 2 Daily distribution of hourly wet bulb globe temperature (WBGT) averages for Inland (blue) and Coastland (red) groups across the harvest. Individual days (dots) plus, hourly averages and SDs across the harvest are represented. Dashed lines indicate the Occupational Safety and Health Administration permissible heat exposure limit values. ${ }^{8}$

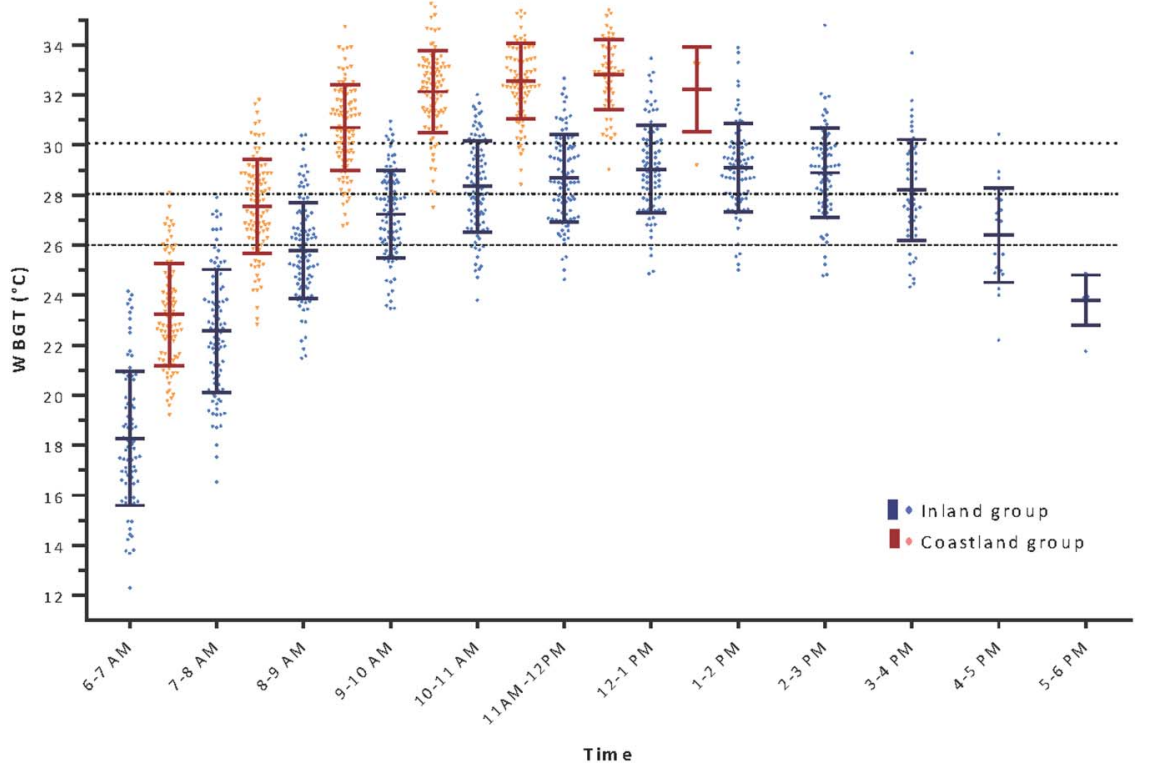


Figure 3 Percentage of Inland workers reporting symptoms of heat stress and dehydration preintervention (January 2015) and postintervention (at the end of harvest, April 2015).

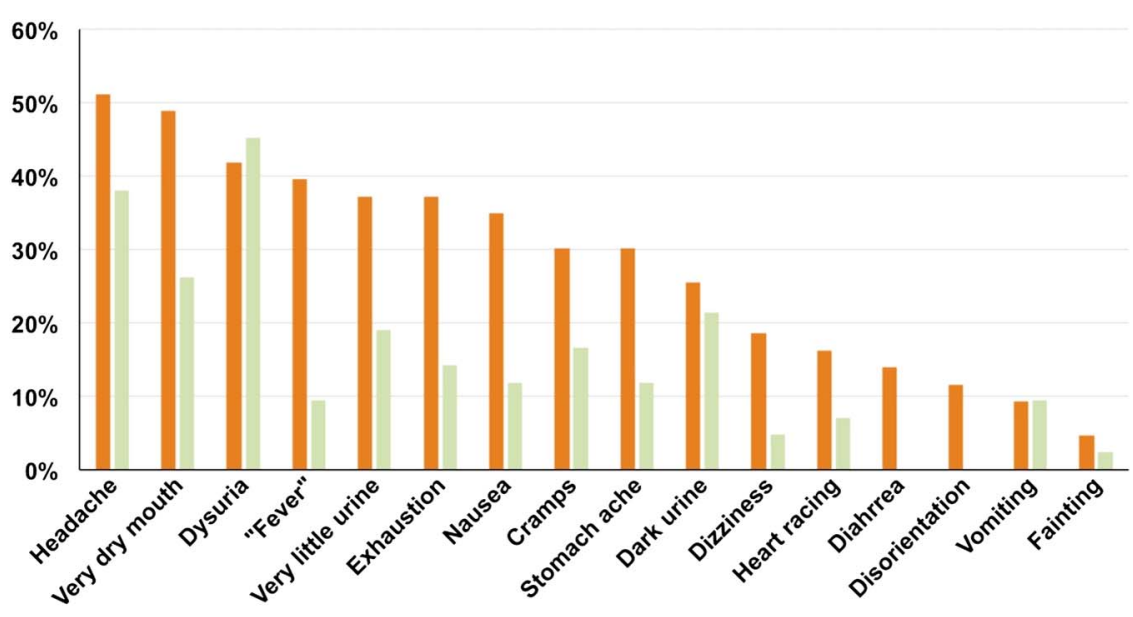

Pre intervention Post intervention improved health status of the workers, for example less fatigue, and, as noted by the caporal, no more cases of heat exhaustion needing medical attention. Research assistants reported workers bringing in lighter colour postshift urine samples.

Some negative feelings about select aspects of the intervention were also expressed. Older workers mentioned not always following the instructions to take rests. The staff professionals needed extra effort to overcome scepticism about managing the WRS intervention which will be addressed with improved communication in Phase 2.

\section{DISCUSSION}

Sugarcane workers (including those from other places who seasonally migrate for cane-cutting jobs) are long-term residents of Mesoamerica. Hence the workforce in general, and the workforce studied, could be considered naturally acclimatised to the background heat and humidity of El Salvador. The relevant aspect of sugarcane agriculture as practiced in this region is the physically demanding nature of the work that is added to the hot background environment. Work in other agricultural settings (cocoa, coffee, bananas, corn, etc), as well as industrial settings (mining, construction, etc), is hard work, but the evidence suggests work in sugarcane harvesting is the most physically demanding of all.

The decision about sample size for Phase 1 was made for the primary objective of testing feasibility and acceptance. However, a sufficient number of study participants were included to permit identifying a large positive or negative effect on health and efficiency. Total number of workers tested in Phase 1 was smaller than planned since we had to postpone the intervention in the Coastland group to next year (see above). Continued discussions with the Coastland group eventually resolved confusions about the study so that, by the end of harvest, 41 of the 45 asked to continue in the study. CamelBaks were distributed to all these participants and we collected final samples on these while continuing to build a relationship for the Phase 2 expanded intervention.

\section{The Water.Rest.Shade intervention}

Rest

The continuous monitoring of WBGT throughout the harvest documented well the extreme nature of the working conditions. The intervention rest schedule designed for this study provided daily rest for approximately $25 \%$ of the workday. Still, over
$40 \%$ of the work hours during the harvest were spent at WBGT levels where a minimum of $50 \%$ rest time is recommended. Notably, the Inland fields reached an average maximum WBGT of $29.3^{\circ} \mathrm{C}$ and included at least $10 \%$ of hours worked at a level where OSHA recommends work be limited to $25 \%$ of the time. $^{8}$ Similar findings have been reported from a study of Costa Rican sugarcane workers.

\section{Water}

The CamelBaks were almost immediately adopted by most workers resulting in a self-reported $25 \%$ increase in mean water consumption. Furthermore, respondents in the focus groups reported that by observing their urine being analysed, they learned that the colour and amount of urine could indicate dehydration, and help them know they needed to drink more water.

\section{Shade}

The qualitative assessment indicated that the cutters found particular benefit from the shade component. They noted that, prior to the intervention they had always brought some water with them, and knew they could rest if they wanted to, but rest breaks were often possible only under direct sunlight. Almost everyone used the shaded area for their rest periods and seemed to enjoy both the comfort and the camaraderie the shaded area offered (figure 1).

\section{Symptoms of heat stress}

The integrated measurement of the impact of the WRS intervention was characterised best by the change in heat-related symptoms that the workers reported (see figure 3). Also in the qualitative study, workers specifically mentioned less or no symptoms postintervention, fewer medications needed for symptoms (also noted by the caporal) and overall being in a better mood.

\section{The efficiency intervention \\ The new machete}

The new machete proved effective in not reducing work efficiency during the intervention. Initially, workers did not have faith in the thinner, less rigid machete, but the first cutters using it convinced the others that it made the work easier. For the most part, the new machete lasted although it did appear it would have to be replaced the next year. 
Fewer rows and more efficient stacking

One demonstration of the impact of fewer rows cut and more efficient stacking was the mill staff response. When they observed the improved efficiency, they introduced the change in number of rows cut for all other cutting fronts despite not having the WRS programme for those teams.

The result of the two changes was a notable increase in work efficiency especially in light of the added rest time over the workday. The intervention group's average preintervention production was lower than in the other five most productive groups (significantly so for three) while average postintervention production was significantly higher than in all but one of the other groups. Some portion of the improvement seen in the other major groups might be explained by adoption of the change in number of rows cut for all cutting fronts after the early success in the Inland group. Whether this difference might be attributed to the new machete, the WRS protocol, or both, cannot be determined.

\section{Perceptions of change}

The qualitative analysis offered important insights about how the intervention was received. For the most part, workers and worker families responded positively to the intervention. The caporal and the workers reported that working conditions had changed. They had believed that the poor working conditions were inevitable, but during the intervention came to realise that conditions could be modified so that, even with the harsh weather circumstances, the work could be improved.

Mill leadership was enthusiastic and supportive of the programme from the onset. By contrast, mill personnel operating closer to the fieldwork initially were concerned about the rather difficult changes and extra work the intervention imposed. It took time and effort from researchers and mill leadership to understand the technical needs of the cane-cutting process, the scientific needs of the intervention and to achieve effective communication. As the intervention became more established and initial difficulties were resolved, the benefits for the workers became evident and the mill personnel were increasingly positive.

\section{Lessons learned}

An intervention, especially on a larger scale, is costly, time consuming and induces a great deal of uncertainty. To achieve the necessary long-term commitment to the change, a notion of ownership by all actors and a willingness to assume responsibility for the different components of the intervention is key. Some of our plans would have been better implemented had we understood the different nature of leadership in the two study groups. Although we did not succeed entirely during Phase 1, several important lessons were learned. We have to be as clear as possible with workers and with mill staff about the intended intervention, the objectives we have in mind, and the need to fit these into the existing work practices and work environment. We emphasise flexibility and openness to different routes to achieve this. One example is that the plan to reduce six-row to four-row cutting had to be modified. The demands on the worker were least with four rows, but the loading equipment used to collect the cut cane could not fit in the narrow spaces created by cutting only four rows.

\section{Overall assessment}

This study is the first formal evaluation of a W.R.S intervention in the sugarcane industry. There were several essential components of the intervention programme, each critical to the initial success demonstrated. First, there was the identification and enthusiastic participation of a willing and collaborative mill owner. Second, there was engaged professional staff at the mill that designed and constructed the shade tents to accommodate circumstances in the field, and the need to move them constantly, and that organised effective delivery of water to the fields on a daily basis. The staff also worked closely with the Australian consultants to implement the efficiency intervention in the process, becoming early converts to the advantages of the new, lighter machete. Third, there was a research staff that willingly and reliably attended to the numerous individual requirements essential to field collection of biological materials and survey administration. Each time the staff went to the field they had to leave their homes before 03:00 and spend the long days in the fields working closely with the cane cutters to collect all necessary data with efficiency and proper care of all sample materials. Biological samples had to be carefully stored and maintained at constant cold temperatures. Good working relationship with workers and staff was crucial. Fourth, the attention and care of the security forces (police and sometimes military escorts) assigned to us by the mill was invaluable. Finally, and at the core of the study, were the members of the sugarcane-cutting workforce and their leader. They understood the reasons for the study and had a high level of commitment to participation. Without this, the study could never have been attempted.

We concluded that it is possible to implement a focused WRS programme for manual sugarcane cutters in conjunction with an efficiency training programme. Although economic analysis is needed to draw cost-benefit conclusions, we found increased productivity and improved work satisfaction that benefits workers and the mill. It was possible to accomplish a repeated and extensive monitoring of work and environmental conditions and biological sampling in the field. By involving key stakeholders and necessary expertise, this study suggests that a scaleup of such an intervention is feasible and could be beneficial to the workforce and to the mill.

Acknowledgements The authors thank Richard Johnson for advice on the study protocol, Victor Ramirez for assistance with data management, Matteo Bottai for assistance with statistical analyses, Samuel Cheuvront for assistance on measuring heat stress in the field, William Santee for advice on measuring environmental heat exposure, Laurie Blanchard for assistance designing the rest break schedule. They also thank Lars Barregård for valuable comments on a previous version of the manuscript. They especially thank the workers who participated, the mill staff who organised and provided the intervention, and the security forces who protected researchers during field work.

Collaborators The following collaborators provided material input to the research and together with the authors comprise the working group: Abrahamson $M$, Apelqvist J, Aragón A, Arias E, Ekström U, Faber D, Peraza S and Rojas M.

Contributors JG conceived and CW prepared the first protocol draft. The final protocol was produced with essential input from all authors. TB, EJ, IW, RG-T collected the field data. DHW was the principal investigator and supervised the project, together with RG-T as local PI. TB was responsible for data management and statistical analyses. RAIL analysed the weather data. All authors contributed to interpretation of the results. TB prepared the first draft, DHW was responsible for all subsequent drafts with input from all authors, and submitted the manuscript. All authors contributed critically to revised drafts with text and intellectual content. Non-author members of the WE Program Working Group either collected different types of data or were responsible for laboratory analyses. All authors of this article have read and approved the final version submitted.

Funding The study was supported by a grant from the Dutch National Postcode Lottery to Solidaridad. In addition, the El Ángel sugar mill funded the interventions studied. None of these entities had a role in the study design, data collection, data analysis, data interpretation, or writing of the report. The corresponding author had full access to all the data in the study, and had final responsibility for the decision to submit for publication.

Competing interests None declared. 


\section{Patient consent Obtained.}

Ethics approval This study was approved by the National Ethics Committee for Clinical Research (Comité Nacional de Ética de Investigación en Salud) of El Salvador (OHRP IRB No. 0005660, FWA No. 00010986).

Provenance and peer review Not commissioned; externally peer reviewed.

Open Access This is an Open Access article distributed in accordance with the Creative Commons Attribution Non Commercial (CC BY-NC 4.0) license, which permits others to distribute, remix, adapt, build upon this work non-commercially, and license their derivative works on different terms, provided the original work is properly cited and the use is non-commercial. See: http://creativecommons.org/ licenses/by-nc/4.0/

\section{REFERENCES}

1 Wesseling C, Crowe J, Hogstedt C, et al., eds. Mesoamerican Nephropathy: report from the first international research workshop on MeN. Heredia, Costa Rica: SALTRA/IRET-UNA, 2013.

2 García-Trabanino R, Aguilar R, Silva CR, et al. [End-stage renal disease among patients in a referral hospital in El Salvador]. Rev Panam Salud Publica 2002:12:202-6.

3 Orantes CM, Herrera R, Almaguer M, et al. Chronic kidney disease and associated risk factors in the Bajo Lempa region of El Salvador: Nefrolempa study, 2009. MEDICC Rev 2011:13:14-22.

4 Peraza S, Wesseling C, Aragon A, et al. Decreased kidney function among agriculture workers in El Salvador. Am J Kidney Dis 2012;59:531-40.

5 Wesseling C, Crowe J, Hogstedt C, et al. The epidemic of chronic kidney disease of unknown etiology in Mesoamerica: a call for interdisciplinary research and action. Am J Public Health 2013;103:1927-30.

6 Johnson RJ, Sánchez-Lozada LG. Chronic kidney disease: mesoamerican nephropathy-new clues to the cause. Nat Rev Nephrol 2013;9:560-1.

7 Crowe J, Wesseling C, Román-Solano B, et al. Heat exposure in sugarcane harvesters in Costa Rica. Am J Ind Med 2013;56:1157-64.

8 https://www.osha.gov/dts/osta/otm/otm_iii/otm_iii_4.html (accessed 5 Jan 2016).

9 Paula Santos U, Zanetta DM, Terra-Filho $\mathrm{M}$, et al. Burnt sugarcane harvesting is associated with acute renal dysfunction. Kidney Int 2015;87:792-9.

10 Lucas RA, Epstein Y, Kjellstrom T. Excessive occupational heat exposure: a significant ergonomic challenge and health risk for current and future workers. Extrem Physiol Med 2014;3:14

11 Lucas RAl, Bodin T, García-Trabanino R, et al. Heat stress and workload associated with sugarcane cutting -an excessively strenuous occupation! [abstract]. Extrem Physiol Med 2015;4(Suppl 1):A23.

12 Cheung SS, McLellan TM, Tenaglia S. The thermophysiology of uncompensable heat stress. Physiological manipulations and individual characteristics. Sports Med 2000;29:329-59.
13 Sawka MN, Cheuvront SN, Carter R III. Human water needs. Nutr Rev 2005;63: S30-9.

14 Sawka MN, Burke LM, Eichner ER, et al., American College of Sports Medicine. American college of sports medicine position stand. Exercise and fluid replacement. Med Sci Sports Exerc 2007;39:377-90.

15 Patel DR, Gyamfi R, Torres A. Exertional rhabdomyolysis and acute kidney injury. Phys Sportsmed 2009;37:71-9.

16 Robey RB. Cyclical dehydration-induced renal injury and Mesoamerican nephropathy: as sweet by any other name? Kidney Int 2014;86:226-9.

17 García-Trabanino R, Jarquín E, Wesseling C, et al. Heat stress, dehydration, and kidney function in sugarcane cutters in El Salvador-a cross-shift study of workers at risk of Mesoamerican nephropathy. Environ Res 2015;142:746-55.

18 Laws RL, Brooks DR, Amador JJ, et al. Changes in kidney function among Nicaraguan sugarcane workers. Int J Occup Environ Health 2015;21:241-50.

19 Laws RL, Brooks DR, Amador JJ, et al. Biomarkers of kidney injury among Nicaraguan sugarcane workers. Am J Kidney Dis 2016;67:209-17.

20 Correa -Rotter R, Wesseling C, Johnson RJ. CKD of unknown origin in Central America: the case for a Mesoamerican nephropathy. Am J Kidney Dis 2014:63:506-20

21 Weiner DE, McClean MD, Kaufman JS, et al. The Central American epidemic of CKD. Clin J Am Soc Nephrol 2013;8:504-11.

22 Ordunez P, Martinez R, Reveiz L, et al. Chronic kidney disease epidemic in Central America: urgent public health action is needed amid causal uncertainty. PLoS Negl Trop Dis 2014:8:e3019.

23 Ordunez $\mathrm{P}$, Saenz $\mathrm{C}$, Martinez $\mathrm{R}$, et al. The epidemic of chronic kidney disease in Central America. Lancet Glob Health 2014;2:e440-1.

24 Jayasumana C, Gunatilake S, Senanayake P. Glyphosate, hard water and nephrotoxic metals: are they the culprits behind the epidemic of chronic kidney disease of unknown etiology in Sri Lanka? Int J Environ Res Public Health 2014;11:2125-47.

25 Orantes CM, Herrera R, Almaguer M, et al. Epidemiology of chronic kidney disease in adults of Salvadoran agricultural communities. MEDICC Rev 2014;16:23-30.

26 Raines N, González M, Wyatt C, et al. Risk factors for reduced glomerular filtration rate in a Nicaraguan community affected by Mesoamerican nephropathy. MEDICC Rev 2014;16:16-22.

27 Correa-Rotter R, Wesseling C, Johnson RJ. In reply to 'Pesticides and the epidemic of CKD in Central America'. Am J Kidney Dis 2014;64:477-8.

28 Wegman D, Glaser J, Johnson RJ, et al. Comment: mesoamerican nephropathynew evidence and the need to act now. Int J Occup Environ Health 2015;21:333-6.

29 Gordon CJ, Leon LR. Thermal stress and the physiological response to environmental toxicants. Rev Environ Health 2005;20:235-63.

30 Crowe J, van Wendel de Joode J, Wesseling C. A pilot field evaluation on heat stress in sugarcane workers in Costa Rica: what to do next? Glob Health Action 2009;2.

31 https://www.youtube.com/watch?v=6bLA8LjqJow (accessed 5 Jan 2016). 